\title{
Re-evaluation of Internationally and Locally Developed ELT Materials in Iran: A Bimodal Approach to Material Development
}

\author{
Mohammad Reza Talebinezhad \\ Islamic Azad University, Shahreza Branch, Iran \\ Email: rtalebinezhad@yahoo.com \\ Masoud Mahmoodzadeh \\ Shaikhbahee University, Iran
}

\begin{abstract}
The present study aimed to investigate the pedagogical applications of bimodality theory in a selection of both internationally-developed (namely, Interchange 3, American Headway 4, \& Summit 1) and locally-developed ELT textbooks (namely, the English textbooks used in Iranian high schools) which are frequently and widely used in Iran. The purpose of this research was first to find out to what extent the textbooks in question follow the pedagogical applications of bimodality theory and second to see if there is any significant difference between the internationally-developed and locally-developed ELT textbooks concerning pedagogical applications of bimodality theory. To this end, the individual textbooks along with their respective teacher's editions were scrutinized closely in terms of the utilized pedagogical techniques and principles of bimodality theory. The quantitative analysis of the data revealed that pedagogical techniques and principles of bimodality theory appear to be significantly more applied in the design of the internationally-developed ELT textbooks than the locally-developed ones. Moreover, the detailed examination of the data also suggested that perhaps one of the main reasons for the inefficiency of the locally-developed ELT textbooks (i.e. the English textbooks used in Iranian high schools) is the marginality of the pedagogical techniques and principles of bimodality theory in them. Thus, in terms of the possible implications of this study, it is suggested that the locally-developed ELT textbooks under study need to be modified in order to be more in line with the pedagogical objectives of bimodality theory.
\end{abstract}

Index Terms-Bimodality Theory, modal principles and techniques, ELT textbooks, ELT teacher's editions

\section{INTRODUCTION}

During the last few decades, a huge diversity of theories and assumptions on Second Language Teaching (SLT) have been proposed, all claiming to account for success documented in the domain of second language teaching and learning. Yet, despite their early relative success from a methodological standpoint, concerns have always been raised about the pedagogical consequences of devising such teaching practices, learning materials, and language syllabuses. And, in fact, as such methods or approaches have intended to implement their theories and assumptions in the relevant teaching contexts, they have failed to meet the needs and expectations of their target language learners to a great extent. The above methodological concerns relate to the notion of SLT Dilemma (Danesi, 2003) which explains that despite considerable research on SLA and SLT, none of the proposed methods and approaches in the past has tacked this dilemma successfully, and thus language learners rarely achieve high levels of proficiency, irrespective of their background or the employed methodology. However, bimodality theory which is one of the recent views of language learning and teaching has attempted to resolve the above dilemma. It claims that neuroscientific constructs could have pedagogical consequences, and that the functions associated with both hemispheres of the brain should be taken into account in Second Language Teaching (SLT), that is, structuring classroom input, designing syllabuses, and doing all the things that are required for carrying out SLT in a classroom environment.

However, as Danesi (2003) discusses, bimodality theory, one of the recent views on SLT which ushered in a new era of research in second language learning and teaching, suggests that the reason that so many methods and approaches in SLT have relatively tended to fail lies in the fact that all of them were in part unimodal, that is, focusing on only one of the two hemispheres of the brain. For example, on the one hand, the methods such as Grammar Translation Method or Audio-lingual Method focused only on the left hemisphere (L-Mode) while, on the other hand, the Communicative, Humanistic, and Neurolinguistic methods and approaches overemphasized the right hemisphere (R-Mode) to the detriment of the L-Mode.

It is safe to mention that the ELT textbooks and materials are also involved in resolving the issue of SLT Dilemma. And, as a result, many studies have been carried out to evaluate ELT textbooks and materials. And, thus, many textbook-evaluation checklists have been introduced (Williams, 1983; Sheldon, 1988; Ur, 1996; to name but a few). But 
perhaps, no such studies have focused on the merits and demerits of the ELT textbooks and materials with regard to the application of the pedagogical principles of bimodality theory. So the present study truly aimed to explore ELT textbooks and materials from a totally different viewpoint to material evaluation, that is, from bimodal approach. More particularly, the study attempted to examine and evaluate the currently used ELT materials in Iran with reference to the pedagogical principles derived from bimodality theory. However, more studies, no doubt, are required to validate the findings of the study because the evaluation of all locally and internationally-produced ELT materials used in Iran is beyond the scope of this study.

\section{RESEARCH QUESTIONS}

The present study attempted to answer the following questions:

1) To what extent are the modal techniques used in the design of the learning activities of both the locally-developed and internationally-developed ELT material under analysis?

2) Is there any significant difference between the locally-developed and internationally-developed ELT materials under analysis in terms of the utilized modal techniques of bimodality theory in the design of their learning activities?

3) To what extent do the locally-developed and internationally-developed ELT materials under analysis follow the pedagogical principles of bimodality theory in terms of their selection or grading of content and their employed methodologies or teaching procedures?

4) Is there any significant difference between the locally-developed and internationally-developed ELT materials under analysis concerning the application of pedagogical principles of bimodality theory?

\section{LITERATURE REVIEW}

As mentioned earlier, the methodological concerns discussed here relate to the notion of SLT Dilemma (Danesi, 2003) which explains that despite considerable research on SLA and SLT, language learners rarely achieve high levels of proficiency, irrespective of their background or the employed methodology. However, to date, some noteworthy reactions have been put forward for the dilemma, namely Kumaravadivelu' (1994) post-method pedagogy, and Ellis's (2003) principles of instructed language learning. But there is one reaction to the dilemma introduced by Danesi (2003) in which the SLT Dilemma is dealt with differently in comparison with the above-mentioned reactions. Danesi (2003) proposed bimodality theory, the theory which attempts to explain and also resolve the SLT Dilemma based on the latest findings of neurolinguistic research and brain studies. To elaborate more on bimodality theory, the tenets and principles of this theory are briefly discussed below.

\section{A. Bimodality Theory}

The concept of bimodality in second language acquisition and learning was developed by Marcel Danesi (1986). The impact of neuroscience on language learning has established, as a fact, that "language learning is a multi-dimensional process that requires an equally versatile and multi-faceted pedagogical response" (Danesi, 1987, p.379). In effect, in terms of the nature of the cerebral learning system, that is, the two hemispheres of the brain being specialized according to function, the only viable teaching approach is one which caters in a complementary fashion to the student's global language processing (Cicogna \& Nuessel, 1993).

As Danesi (2003) states, any instructional system that privileges only one of the two modes of brain is bound to fail sooner or later because such a system has been unimodally developed. According to Kim-Rivera (1998, p. 97) the two hemispheres process language input as a unit and are thus complementary: the left hemisphere enables us to analyze individual concepts, while the right hemisphere allows us to synthesize information into discourse.

The research and advances of neurophysiology have habitually affected language pedagogy, with the last two decades cultivating bimodality to a greater degree and exhibiting its most prosperous offerings. At the end of the 19th century, the designation of the left hemisphere as major or dominant and the right as weak or minor caused teaching methods to be unimodal, that is, to concentrate on the structural form of language (Danesi, 1988). The pedagogical implications of this signified a tendency to neglect those features associated with the right hemisphere (usually the creative/artistic qualities). Further research continued to strengthen the views that the left hemisphere was programmed for form and the right controlled content, in that it deciphered new stimuli in an efficient manner (Danesi, 1988). Therefore, the methods that pursued grammatical linguistic competence only exercised the left hemisphere actively (cited in Antenos-Conforti, 2001, pp.30-31).

Although the techniques utilized in inductivist and deductivist methods focused on developing L-Mode control of second language, it should be noted that some of the techniques used in the inductivist method, for instance the use of the situational practice, the incorporation of visual stimuli, the contextualization of practice routines, etc., did have an R-Mode focus. This might explain why they have survived to this day as effective techniques on their own (Danesi, 2003).

However, on the other hand, Communicative, Humanistic, Neurolinguistic methods and approaches were designed with an opposite unimodal bias. They typically overemphasized and utilized R-Mode functions to the detriment L-Mode functions. This is why they always generated much interest at first, but seldom produced high level of proficiency at the 
end of a course of study. Moreover, it should be noted that no method or approach has ever been designed intentionally to be unimodal. It is more accurate to think of SLT practices generally as placeable on a continuum with two extreme LMode and R-Mode endpoints( i.e. GTM \& Silent Way methods, respectively)at which bimodality theory suggests the mid-point of this continuum as the most appropriate for SLT practice(Danesi, 2003, p.49).

As Kim-Rivera (1998) notes, the two hemispheres process language input as a unit and are thus complementary: the left hemisphere enables us to analyze individual concepts, while the right hemisphere allows us to synthesize information into discourse. Nevertheless, as Danesi and Mollica(1988) noted, bimodality does not dictate any specific instructional routine or style, it can be adapted into any textbook, regardless of emphasis. Thus, this theory is compatible with the notion of proficiency in that it is a multifaceted concept that adapts to all methodologies, approaches, and techniques.

\section{B. Modal Principles of Bimodality Theory}

They are four pedagogical principles which are derived from the recent relevant brain research corresponding directly to the application of bimodality theory in SLT. Danesi (2003) introduced these principles as follows: (1) the modal flow principle; (2) the modal focusing principle; (3) the contextualization; (4) the conceptualization principle. The consolidation of these principles would effectively enhance the learning of the language, as they integrate both structure and communication, and thus educate both hemispheres at the same time. Danesi and Mollica (1988) conducted a study which attempted to substantiate the claims of bimodality theory. It was a comparison study of the measurable learning outcomes of teaching in a bimodal fashion, employing techniques suggested by the principles, and in an L-mode dominant manner and an R-mode dominant manner. The "very rapid assessment" sought the viability of pursuing bimodality, and revealed that, with the three groups as distinguished above, the bimodal group equaled both the L-mode and R-mode groups in their respective strengths and was the far superior group in regard to general proficiency and creativity.

\section{The Modal Flow Principle}

By definition, the modal flow principle (also known as modal directionality principle) signifies that at first the experiential plane is activated (the R-mode), then new input flows to the analytical (the L-mode), as was generally the case with the inductive principle (Mollica \& Danesi 1998, p.209). However, the principle of modal directionality should be utilized only with new input, so that foreign language learners may experience a new structure or concept before shifting to the formal explanation. Young and Danesi (2001) discuss that during the initial learning stages students need to assimilate new input through observation, induction, role-playing, simulation, oral tasks, and various kinds of interactive activities. But we would quickly add that formal explanations, drills, and other L-Mode procedures must follow these stages, since we have found that control of structure will not emerge spontaneously.

The modal directionality principle implies, above all else, that the teacher should leave ample room for student improvisation during the early learning stages. Instructional techniques which focus on explanations will be of little value, since the students generally have no preexisting L-Mode schemata for accommodating the new input directly. In order to make the new material accessible to the L-Mode (intake), therefore, the early stages should involve teacher and learner alike in activities enlisting exploration, imagination, spontaneity, and induction. Once the initial learning stages have been completed, the teacher can "shift modes" and begin to focus more on formal, mechanical, rule-based instruction (Young \& Danesi, 2001, p.86). Thus, modal directionality can be seen to be a different version of the oldest principle in teaching - the inductive principle. But unlike its use in strictly inductivist methods, it does not require the deployment of induction for all learning tasks, only those that involve new input. Thus, if a learning task contains knowledge or input that the learner can already accommodate cognitively, directionality can be efficiently avoided. To support this principle, there is a lot of indirect evidence throughout the SLA and SLT literatures. For example, Jeffries (1985) has showed that the use of grammatical rules to start a new unit of learning (an R-Mode practice) poses a serious obstacle to class room acquisition. The modal directionality principle thus claims: (1) that experiential forms of tutoring belong to the initial learning stages, (2) that teaching should move progressively towards a more formal, analytical style in the later stages, and (3) the creative utilization of the new input belongs to the final stages. And, these stages can be called simply an R-Mode stage, an L-Mode stage, and an intermodal stage respectively (cited in Danesi, 2003, pp. 5152). Danesi (2001) also maintains to identify the general procedures being utilized in any teaching context based on the modal flow principle as follows:

During an R-Mode Stage:

*Classroom activities should be student-centered and involve students and teacher in a complementary fashion.

* Novel input should be structured in ways that activate sensory, experiential, inductive forms of learning (dialogues, questioning strategies, simulations, etc.).

*The students' inductive and exploratory tendencies should be encouraged to operate freely when introducing new information.

During an L-Mode Stage:

*The focus now shifts to the teacher. The teacher should explain the structural and conceptual features of the new materials clearly using deductive and inductive techniques as warranted by the situation.

*Explanations, drills, etc. should follow the experiential learning phases. 
*Focusing on some problematic aspect of the subject being taught is to be encouraged if a student appears to have difficulty grasping it or using it with appropriate comparison to the NL and with suitable exercise materials.

During an Intermodal Stage:

*The learner should be allowed to employ the new materials to carry out real- life verbal tasks, but only after he/she shows the ability or willingness to do so.

*Teaching new things or discussing matters of form and structure during this stage should be avoided.

*Students should be allowed to find solutions to problems of communication on their own.

*Role-playing and work in pairs or groups is advisable for most students, although some may not wish to participate. The latter can be assigned other kinds of creative tasks (e.g. writing).

\section{The Modal Focusing Principle}

Modal focusing principle is required at points in the learning process when, for instance, a learner appears to need help in overcoming an error pattern that has become an obstacle to learning. To this end, L-Mode focusing allows the students an opportunity to focus on formal matters for accuracy and control while R-mode focusing attempts to focus on matters of understanding and conceptualization. According to Young \& Danesi (2001), the modal focusing principle in no way implies that mechanical practice be conducted in an uncontextualized way. On the contrary, meaningful contexts should always be provided not only for new input, but also for focusing routines. This allows the R-Mode to complement and strengthen the intake operations of the L-Mode, especially during more mechanically- oriented focusing tasks. Contextualized instruction enables the learners to relate L-Mode form to R-Mode content (p.89).

Also, the modal focusing principle stresses the fact that, at some time during the learning process, the student may need to concentrate on one mode or the other to digest new data, reinforce acquired structures or vocabulary, or simply think of what to say. 'True acquisition can be said to occur when the students' attempts at discourse formulation can be seen to enlist both modes in a cooperative way" (Mollica and Danesi 1998, p.210).

\section{E. The Contextualization Principle}

As discussed by Danesi (2003), memorizing or pronouncing words in isolation, rehearsing speech formulas, or even practicing grammar without reference to some situation that typically entails them, rarely leads to learning. The reason is that language derives its meaning (usage) primarily from the context in which it is involved (i.e. its use). So, without sufficient context, it is unlikely that the brain can assimilate new input in any mnemonically functional way.

Danesi(2003) also maintains that during an R-Mode stage, the new material must contain references to cultural concepts in order for the brain to detect the appropriate meaning potential of the new structures whereas, during an LMode stage, the practice and rehearsal of the new structures is greatly enhanced if practical or conceptual information is provided. Essentially, there are two types of cultural techniques: (1) Cultural contextualization techniques, which are designed to provide culturally appropriate information that allows students to relate the novel linguistic input to cultural concepts, symbolism, rituals during an R-Mode stage. (2) Practical contextualization techniques, which refer to the use of meaningful information or reference to realistic situations in the design of exercises and activities used during an LMode stage (pp. 57-59).To sum up, by contextualization, Danesi means the creation of an environment in which an activity may be situated. This means the avoidance of structure-based pattern drills that focus on linguistic forms rather than the context in which conversation takes place (Cicogna \& Nuessel, 1993). In fact, when the learning task is LMode, supporting contexts should be provided in a process called contextualization. Among contextualization techniques are the use of open dialogues, authentic texts, and realia. Through these techniques grammar can be taught in context (Kim-Rivera, 1998, p.97).

Danesi (1987) states an example in verb conjugation and the differentiation of verb tense which promotes contextualization through the inclusion of a logical nexus in the sentence so that the exercises do not occur in isolation (i.e., only the L-mode is activated). By utilizing a nexus, the R-mode feature is triggered, and the student focuses simultaneously on situational principle and situational context (in choosing the correct verb form). The overall effect of contextualization allows the teacher to deal with grammar as a 'process' rather than a meaningless form (cited in Antenos-Conforti, 2001, pp.32-33).

\section{F. The Conceptualization Principle}

Danesi (2003) discusses that a common observation of teachers is that students often produce L2 messages which are "semantically anomalous" when they attempt to speak or write spontaneously without some form of guidance. Danesi identifies the source of such anomaly in the unconscious tendency of learners to put together L2 messages on the basis of L1 concepts. Thus, the language teacher must ensure that the two systems- the linguistic and the conceptual- are interrelated during all aspects and stages of instruction and practice.

Moreover, Danesi (2003) maintains that in terms of dealing with incoming conceptual structures, the language teacher should attempt to apply the first two pedagogical principles( i.e. modal flow \& modal focusing principles) respectively while bearing in mind that conceptualization can manifest itself in one of these three ways: (1) it can be isomorphic (which of course rarely occurs), that is, L1 and L2 reflect the same conceptual structures;( 2) overlapping, that is, the conceptual structures have overlapping domains;(3) differentiated, that is, L1 and L2 reflect totally different conceptual structures. 
This principle attempts to step outside of the learner to consider how the L2 being learned may influence the individual, the internal restructuring which is brought about by the acquisition of L2, and the compromises which must be reached in order for a language to be acquired and come to be integrated into the individual's personality. If language itself may be seen as human - a container for the life experiences of a whole culture or people- then one cannot approach language teaching or even communication as a mathematical equation where $1+1=2$. Each word in the target language is represented by a sound: each sound is linked to a meaning and image/concept which may or may not coincide with the learner's L1 (Colella, 1999, p.142).

In addition, Danesi (1993) argues that grammatical and lexical categories are also correlated to concept categories and experience. The student learning a L2 must thus learn about the life of the language through his/her understanding of concept boundaries, metaphorical usage, proverbs, and conceptual domains. Included in this domain of language are also al1 the nonverbal language of a target culture such as gestures, tone, social interactions and register.

The metaphorical nature of a language is not only limited to conceptual domains but it has been confirmed that grammatical structures also share this attribute. Consider for example, the use of the Italian prepositions in and $a$ to indicate traveling to cities, regions, countries, or large islands. The Italian in/a can be contrasted to the English to, which not only does not share a similar dichotomy of containment, but also conceptualize traveling to a location as a mere matter of movement and directionality( Danesi, 1998).

\section{G. The Modal Techniques}

According to Danesi (2003), a technique is any procedure that can be used to help accomplish certain objectives or tasks in class. It can be an explanation of grammar, a type of exercise or activity, a test, etc. that has an identifiable RMode, or L-Mode, or intermodal focus in its design. These techniques can be categorized generally as Structural Techniques, Visual Techniques, Ludric Techniques, Humor Techniques, and Role-Playing Techniques (p.104).

According to Danesi (2003), the aim of structural techniques is the development of some aspect of linguistic, communicative, or conceptual competence. These techniques include teacher explanations of grammar and vocabulary, classroom exercises and activities. Most of these techniques have either an R-Mode or an L-Mode focus while some are also intermodal, such as translation exercises or cloze test techniques. Visual techniques provide either: (1) visual contexts to accompany the verbal input, or else (2) provide illustrative support for some explanation, exercise, activity, etc. Thus, they can provide crucial R-Mode contextualization for learning. In addition, in terms of conceptualization principle, they can facilitate the development of the conceptual competence in learners if the provided visual imagery is illustrative of the conceptual domain being learned.

Danesi (2003) also maintains that ludric techniques refer to any game- playing or problem-solving techniques including crosswords, word searches, scrambled words, interactive games, board games, etc. These techniques fall into two categories: Language Teaching Games (LTGs) which are useful during intermodal stages; and Language Teaching Puzzles (LTPS).The LTP techniques are also of two types: form-based LTPs which promote L-Mode form-based language learning; and concept-based LTPs which promote both R-Mode communication-based learning and conceptual fluency. Riddles, logical deductions, simple mathematical puzzles fall into this category. Humor techniques are designed to evoke humor with a crucial R-Mode focus and are useful to develop conceptual fluency in learners. And they are also in line with the conceptualization and contextualization principles. And finally, role-playing techniques are designed to involve learners to communicative together in a creative fashion during intermodal stages; and they include pair work or group work tasks which are particularly useful for bimodal learning.

As mentioned by Antenos-Conforti (2001), due to the possible controversies regarding techniques that may be questionably bimodal, Danesi (1991) examined the issues of how psychologically meaningful it was to label technique $\mathrm{X}$ as right-hemispheric and $\mathrm{Y}$ as left-hemispheric. The method used was Lateral Eye Movement (LEM), which is based on the premise that in most (right-handed) people the activation of left-hemispheric functions causes the eyes to shift their glance to the right. This quick assessment of the bimodal classifications of techniques resulted in the LEM findings that did not contradict the techniques used in the Danesi and Mollica study (1988).

\section{THE STUDY}

To find answers to the above questions, the researchers adopted the Biomodality Models based on Danesi (2003) as the framework for the analysis of the course books in question. The following is the procedure for the description of the materials used and the steps taken in analyzing them.

\section{A. The Corpus}

The materials used in the present study include five ELT textbooks along with their respective teacher's editions which all serve as the corpus of the study. Moreover, the materials fall into two distinct groups: two locally-produced ELT textbooks plus their teacher's editions, and three internationally-produced ELT textbooks plus their teacher's editions.

The former group consisting of two locally-produced ELT textbooks (two English books used in Iranian high schools) plus their respective teacher's edition are listed below:

1) Birjandi, P. et al. (2008). English Book 1. Tehran: Iran Publications. 
2) Birjandi, P., Noroozi, M., Mahmoodi, Gh.H. (2009). English Book 2. Tehran: Iran Publications.

Birjandi, P. (1994). Teacher's Guide Book 1 and 2. Tehran: Iran Publications.

The rationale and criteria for the selection of these textbooks are as follows:

a) This series of textbooks which have been prescribed for use in Iranian high schools by the Ministry of Education are used in Iran to a great extent. Thus, they represent a relatively suitable sample of the locally-developed ELT textbooks already in use in Iran.

b) They are claimed to have been written and designed by some well-known Iranian ELT experts.

c) They are all assumed to cover the four macro-skills throughout their syllabuses.

d) Finally, these two English textbooks also contain available teacher's editions which have been distributed only to high school English teachers by the Ministry of Education in Iran. Thus, their teacher's editions can manifest the types of the methodologies and teaching procedures that teachers are assumed to employ in their teaching performance. Also, it should be mentioned that the content of these two textbooks has been carefully examined from 1994 to 2009 and, since no worthwhile change was found in the compared textbooks, the only available teacher's edition for these textbooks published in 1994 was used as a teacher's edition for these textbooks. It is worth mentioning that English Book 3 which is also taught to senior high school students is not included in the corpus of this study since no respective published teacher's edition was found for this textbook. In other words, this textbook was excluded from the initiallydeveloped corpus of the present study since it did not fulfill the last criterion for selecting the corpus of the study.

The latter group consisting of the three internationally-produced ELT textbooks plus their respective teacher's editions are listed below:

1) Richards, J., Hull, J., Proctor, S. (2005a). Interchange 3( $\left.3^{r d}\right)$. Cambridge: Cambridge University Press.

Richards, J., Hull, J., \& Proctor, S. (2005b). Interchange: teacher's edition 3( $\left.3^{\text {rd }}\right)$. Cambridge: Cambridge University Press.

2) Saslow, J., Ascher, A. (2006). Summit: English for Today's World 1. Longman: Pearson Education.

Saslow, J., Ascher, A., Tiberio, S.C. (2006). Summit 1: Teacher's Edition and Lesson Planner. Longman: Pearson Education.

3) Soars, L., Soars, J. (2005). American Headway 4. Oxford: Oxford University Press.

Soars, L., Soars, J., \& Sayer, M. (2005). American Headway Teacher's Book 4. Oxford: Oxford University Press.

To characterize the features of the above-mentioned textbooks, they are elaborated below in terms of the established criteria for their selection which can directly contribute to the aim of the study. The criteria for the selection of these textbooks are:

a) They are widely used in foreign language institutes in Iran, and that they are communicative textbooks covering the four macro-skills throughout their syllabuses. However, it should be noted that the textbooks in question represent a relatively suitable sample of the internationally-developed ELT textbooks used frequently in Iran. And that this sample is by no means absolutely prefect in terms of representing all the internationally-developed ELT textbooks widely used in Iran.

b) In case of consistency in the chosen textbooks, much attention has been paid to selecting these textbooks because they all represent the same level of proficiency (i.e. Upper-Intermediate).

c) They have been recently designed by some internationally well-known applied linguists and experienced ELT experts such as Jack C. Richards or John and Liz Soars. And that the authors of such textbooks have expressed that much attention has been paid to designing them according to the recent developments in the theories of SLA and SLT.

d) They also contain available teacher's editions which can indicate the types of the methodology and teaching procedures that teachers are supposed to deal with in their teaching performance.

e) Finally, they have been published by three internationally well-known publishers which have received much world-wide attention and are extensively used around the globe.

Since it was felt that there is a need to examine more than two internationally-developed ELT textbooks meeting the above-mentioned criteria to achieve a more reliable sample in the present study, the latter group includes one more ELT textbook than the former group.

\section{B. Procedure}

Following the classification of the materials used as the corpus of the study, the researcher attempted to analyze and evaluate each of them with regard to the application of the pedagogically-oriented principles of bimodality theory.

To begin with, to achieve a suitable sample representing all the full textbooks used in the study, the researcher aimed to scrutinize the first half of the units of these textbooks. To this end, all exercises and activities included in the first half of the units of the textbooks were examined with respect to the frequency of the' modal categories' (i.e. R -Mode, LMode, or Intermodal) used in their design to identify their main modal status and to figure out to which of these three modal categories they belong. And then, an in-depth discussion of the obtained results was provided to elaborate on them thoroughly.

Secondly, the first half of the units of the individual textbooks and their respective teacher's editions were examined based on the three pedagogical principles of bimodality theory (i.e. the modal flow principle, the contextualization principle, and the conceptualization principle) which are described and suggested for the ELT practitioners by Danesi (2003).The obtained results were then discussed in detail to figure out to what extent they follow these pedagogical 
principles in terms of their selection or grading of content and also their employed methodologies or teaching procedures.

Also, note that the modal focusing principle of bimodality theory was first intended to be investigated in detail throughout the textbooks under study. But after the initial examination of the textbooks, it was concluded that this principle perhaps can not be analyzed systematically due to the absence of the practical role of teachers in the present study. In other words, since this principle, unlike the other three principles, necessarily entails the active participation of language teachers to identify the various points in a course of study when there is an urgent need to help individual learners to overcome their learning obstacles, this principle may not be directly applied beforehand in the design of the textbooks and their teacher's editions. To sum up, it seems that ELT textbooks and their teacher's editions can not alone aim to characterize the quality of this particular modal principle effectively unless they totally take into account the crucial role of teachers in applying it practically in different teaching contexts.

However, it is important to note that there are some sections or teaching notes included in the internationallyproduced ELT textbooks plus their teacher's editions (e.g. Checkpoint section or Corpus Notes in Summit 1, Progress Check section or Tip in Interchange 3) which are intended to allow teachers to focus on the progress of learners and also pinpoint any areas of particular difficulty that may require additional instruction and practice. But as was discussed earlier, these sections or teaching notes may not represent the quality of the modal focusing principle in these textbooks effectively due to the absence of the practical role of teachers in this study. Moreover, the analysis of matters such as the physical make-up or the administrative concerns of the materials under evaluation are not dealt with in this study; and also that the type of material evaluation investigated here is a reflective (post-use) material evaluation.

\section{Data Analysis}

Firstly, through performing a page-by-page systematic quantitative analysis of the exercises and activities included in the first half of the units of the textbooks under study, frequency counts and percentage indexes were reported for their main modal status. Secondly, through a systematic quantitative examination of the first half of the units of the individual textbooks and their respective teacher's editions, frequency counts and percentage indexes were also reported for the occurrence of each of the three pedagogical principles of bimodality theory throughout the different sections of the investigated units in the textbooks. Throughout the data analysis process, the researcher was mindful of the possible occurrence of interpretive biases resulting from distinctive differences in the brand of the ELT textbooks under study (namely, the locally and internationally-developed ELT textbooks).

\section{RESULTS AND DISCUSSION}

To address the first research question, the samples of the textbooks (i.e. all exercises and activities included in the first half of the units of the individual textbooks) were examined with respect to the frequency of the 'modal categories' used in their design to identify their main modal status and to figure out to which of the three modal categories (i.e. RMode, L-Mode, Intermodal) they belong. After a close scrutiny of the activities and exercises, they were classified based on their modal category and then frequency counts and percentage indexes were calculated for the scrutinized activities and exercises of the textbooks. It is worth mentioning that some learning activities in the textbooks consist of two individually different activities within themselves in terms of modal categories, but labeled as just one single learning activity. In order to identify correctly the main modal status of these complex learning activities, first they were atomized and then were scrutinized separately with reference to the activity description or explanation provided for them in the teacher's editions.

The results of the analysis are shown below:

TABLE 1.

THE FREQUENCY OF MODAL CATEGORIES USED IN THE LEARNING ACTIVITIES OF INDIVIDUAL TEXTBOOKS.

\begin{tabular}{|l|l|ll|ll|ll|}
\hline Textbooks & No. of units & $\begin{array}{l}\text { R-Mode } \\
\text { No. }\end{array}$ & \% of total & $\begin{array}{l}\text { L-Mode } \\
\text { No. }\end{array}$ & \% of total & $\begin{array}{l}\text { Intermodal } \\
\text { No. }\end{array}$ \\
\hline English Book 1 & 5 & 13 & 12.6 & 71 & 68.9 & 19 & 18.4 \\
\hline English Book 2 & 4 & 10 & 11.3 & 65 & 73.8 & 13 & 14.7 \\
\hline A. Headway 4 & 6 & 116 & 30 & 194 & 50.2 & 77 & 19.7 \\
\hline Interchange 3 & 8 & 93 & 29.7 & 81 & 25.8 & 139 & 44.4 \\
\hline Summit 1 & 5 & 22.7 & 85 & 55.1 & 102 & 42.1 \\
\hline
\end{tabular}

As shown in Table 1, the results reveal that a high percentage of the learning activities of the locally-developed ELT textbooks under investigation are designed with L-Mode focus which are mainly structural techniques including a series of practice drills such as substitutions, transformations, fill-ins, and completions, where as only a small number of the learning activities in these textbooks are designed with R-Mode or Intermodal focus. Moreover, these exercises seem to emphasize the priority of grammatical structures over the communicative skills throughout these textbooks and this is perhaps one of the main demerits of these textbooks in terms of applications of bimodality theory.

In other words, the excess of L-Mode exercises along with the obvious lack of pair work or group work communicative tasks throughout the textbooks in question hinders the applicability of the pedagogical principles of 
bimodality theory, since the optimal implementation of these principles entails the design of more R-Mode and Intermodal activities in these textbooks. On the other hand, according to Table 1, the learning activities of the individual internationally-developed ELT textbooks are elaborated below in terms of the utilized modal techniques. To begin with, it should be noted that American Headway 4 has been designed with fewer Intermodal activities (19.7\%) in comparison with the other two internationally-developed ELT textbooks. In addition, the main features of this particular textbook include numerous structural techniques with L-Mode focus to reinforce the treatment of grammar and vocabulary, a lot of pair work or group work jig-saw activities designed for communicative interaction, numerous use of visual techniques to provide the visual contexts, adequate use of comic strips functioning as humor techniques to enhance the conceptual domains being learned, and finally some role-playing techniques to practice functional language in different social contexts. Also, note that no interactive game was identified in this textbook.

The next internationally-developed ELT textbook, that is, Interchange 3 consists of fewer L-Mode learning activities as compared with the other two internationally-developed ELT textbooks under study. In addition, this textbook benefits from a few interactive games, an adequate use of visual and role-playing techniques, and also a variety of different pair work and group work communicative tasks such as opinion-sharing activities. Also, note that the lack of humor techniques is clearly evident throughout this textbook. As was mentioned earlier, humor techniques are designed to evoke humor with a crucial R-Mode focus and are useful to develop conceptual fluency in learners. And they are also in line with the conceptualization and contextualization principles. And finally, the last internationally-developed ELT textbook under investigation, that is, Summitl like the other two afore-mentioned textbooks benefits from a number of visual techniques used to provide the visual contexts for the tasks or to enhance the learning of the new concepts, a few role-playing techniques, and also numerous pair work and group work activities such as problem-solving activities. Meanwhile, it should be mentioned that this textbook lacks the use of humor techniques and interactive games.

To answer the second research question, the frequencies of the modal categories were compared across the two groups as indicated below:

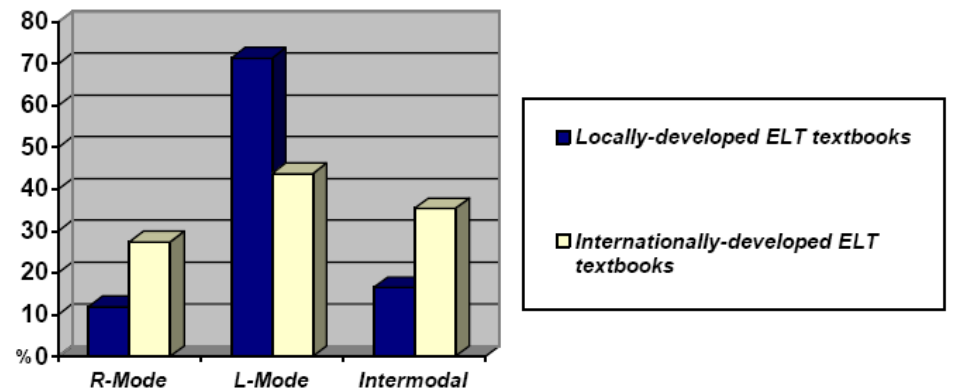

Figure 1. Comparison of the frequency of modal categories used in the learning activities of the textbooks across the two groups

As shown in Figure 1, it seems that the learning activities included in the locally-developed ELT textbooks mostly belong to the L-Mode modal category, since they are designed with L-Mode focus to a great extent (71\%) whereas, only $12 \%$ and $16 \%$ of these learning activities are designed with R-Mode and Intermodal focus respectively. On the other hand, according to Figure 4.1., it seems that clearly fewer L-Mode techniques (43\%) but a lot more R-Mode $(27 \%)$ and Intermodal techniques $(35 \%)$ have been utilized in the learning activities of the internationally-developed ELT textbooks as compared with the locally-developed ones. To answer the third research question, the frequencies of the utilized pedagogical principles of bimodality theory in different sections of the locally-developed ELT textbooks along with their respective teacher's editions were calculated and then tabulated (See Appendices A \& B).

The obtained results suggest that the locally-developed ELT textbooks follow the modal flow principle only in the Reading section and that they are not in line with the modal flow principle in other sections. In addition, these textbooks can function more appropriately during the L-Mode stage than the R-Mode stage or Intermodal stage, since they seem to emphasize the priority of grammatical patterns over the communicative skills. Also, it should be noted that the specifications regarding the identified occurrences of the modal flow principle in these textbooks are also presented in the present study (See Appendices F \& G).

However, it seems that these textbooks are more likely to follow the application of bimodality theory in terms of the other two pedagogical principles, especially the contextualization principle. Also, in contrast to the internationallydeveloped ELT textbooks, these ELT textbooks lack the use of designed audio-contexts and only favor the use of visual contexts. Therefore, the locally-developed ELT textbooks may not contextualize or conceptualize the new learning materials in a culturally appropriate fashion due to the absence of the designed audio-contexts. To continue answering the third research question, the frequencies of the utilized pedagogical principles of bimodality theory in different sections of the internationally-developed ELT textbooks along with their respective teacher's editions were also calculated and then tabulated (See Appendices C, D, \& E).

According to the obtained results, the internationally-developed ELT textbooks tend to follow the pedagogical principles of bimodality theory to a relatively large extent, since the effective utilization of the pedagogical principles can be clearly seen in the design of the different sections of these textbooks. Moreover, among the ELT textbooks in 
question, Summit 1 seems to have achieved a relatively higher percentage for each individual pedagogical principle. In contrast to the locally-developed ELT textbooks, the internationally-developed ELT textbooks seem to function during the R-Mode stage and Intermodal stage as effectively as during the L-Mode stage. And, both visual and audio contexts along with questioning strategies have been used to accompany the new learning materials and consequently activate the crucial R-Mode stage. Also, the specifications concerning the identified occurrences of the modal flow principle in these textbooks are presented in the present study (See Appendices H, I, \& J).

To answer the last research question, the frequencies of the three pedagogical principles of bimodality theory were compared across the two groups. The results are shown in the following figure:

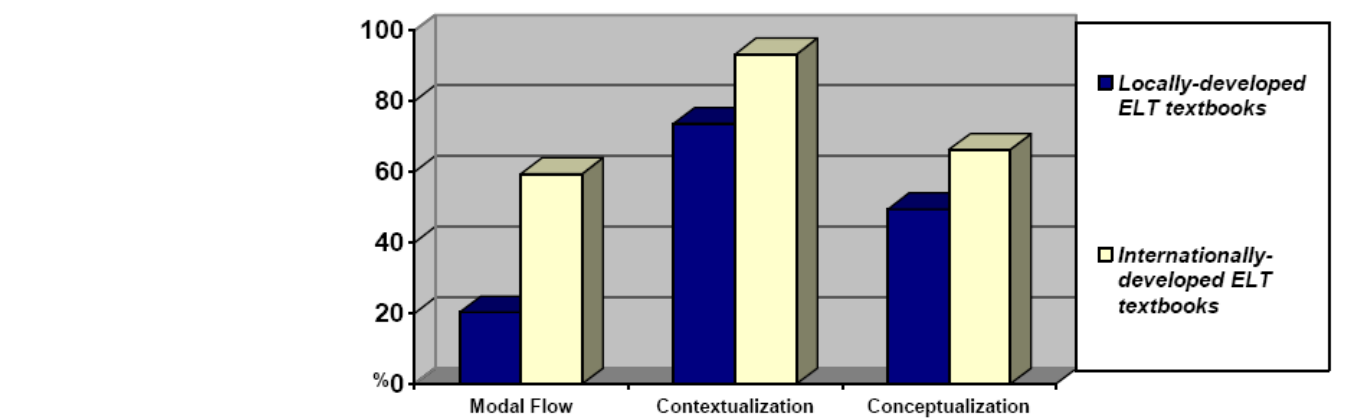

Figure 2. Comparison of the frequency of pedagogical principles of bimodality theory applied in the ELT textbooks and their respective teacher's editions across the two groups.

As shown in Figure 2, the findings suggest that the internationally-developed ELT textbooks are significantly more in line with the application of bimodality theory than the locally-developed ELT textbooks, since the former ELT textbooks exceed the latter ELT textbooks in terms of the applied pedagogical principles of bimodality theory.

Also, more specifically, the above results suggest that the role of the modal flow principle has been greatly marginalized in the design of the latter ELT textbooks. Accordingly, the application of this particular principle is perhaps represented less optimally in the latter ELT textbooks than the former. Furthermore, the results also reveal that the contextualization principle seems to be more applied in the design of both groups of the ELT textbooks as compared with the other two pedagogical principles of bimodality theory.

\section{CONCLUSION}

In sum, as mentioned earlier, the present study generally intended to investigate the application of the recently developed principles of bimodality in the design of both the locally-designed and internationally-designed ELT materials used widely in Iran. To this end, the ELT textbooks under investigation along with their respective teacher's editions were meticulously scrutinized to determine the extent to which these materials follow the pedagogical implications provided by bimodality theory.

The results of the present study suggest that the use of modal techniques of bimodality theory is significantly more dominant in the design of the learning activities of the internationally-developed ELT textbooks than the locallydeveloped ones. Thus, the results perhaps confirm that in terms of the shortcomings identified in the learning activities, the locally-developed ELT textbooks need to be revised and revamped in order to be more in line with the pedagogical applications of bimodality theory proposed for the syllabus designers of ELT textbooks. Furthermore, the overall findings of the study indicate that the analyzed pedagogical principles of bimodality theory in the ELT textbooks under study appear to be significantly more applied in the design of the different sections of the internationally-developed ELT textbooks than the locally-developed ones. Also, perhaps one of the main reasons that the locally-developed ELT textbooks under study have fulfilled neither the expectations of their EFL learners/teachers nor their syllabus designers is due to the inadequate use of the pedagogical applications of bimodality theory in the design of these textbooks. Thus, it is suggested that identified shortcomings of these textbooks and their teachers' edition need to be modified and improved based on the principles and techniques of bimodality theory to meet the expectations of both their EFL learners/teachers and their syllabus designers. However, as mentioned earlier, one of the limitations of the present study is that the modal focusing principle of bimodality theory has not been analyzed and investigated in this study, since this principle needs to be practically examined in an experimental study aimed to analyze the teaching procedures applied by language teachers in the classroom.

To sum up, based on the practical implications provided in the present study, it is suggested that perhaps one of the crucial reasons for the inefficiency of the locally-produced ELT textbooks (i.e. the English textbooks used in Iranian high schools) is related to the marginality of the pedagogical techniques and principles provided by bimodality theory. In conclusion, there may be an essential need for the locally-developed ELT textbooks plus their teacher's editions to be modified by the Iranian syllabus designers to follow and endorse more the practical application of bimodality theory. In terms of the possible suggestions for further research, it is suggested that more similar studies can be planned to validate 
the findings of the present study; and also some experimental studies can be carried out investigating practically the application of bimodality theory in EFL/ESL classrooms.

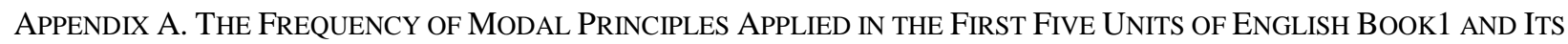
TEACHER'S EDITION.

\begin{tabular}{|c|c|c|c|}
\hline & Modal Flow Principle & Contextualization Principle & Conceptualization Principle \\
\hline Unit Sections & No. $\quad \%$ of total & $\%$ of total & $\%$ of total \\
\hline New Words & 0 & 100 & 100 \\
\hline Reading & 100 & 100 & 40 \\
\hline Speak Out & 20 & 80 & 40 \\
\hline Write It Down & 0 & 20 & 20 \\
\hline Lan. Functions & 0 & 100 & 100 \\
\hline Pronunciation & 0 & 60 & 0 \\
\hline
\end{tabular}

Note: Lan. Function (Language Function).

ApPendix B. The Frequency of Modal Principles ApPlied in the First Four Units of English BoOK 2 AND ITS TEACHER'S EDITION.

\begin{tabular}{|c|c|c|c|}
\hline Unit Sections & $\begin{array}{l}\text { Modal Flow Principle } \\
\text { No. } \quad \% \text { of total }\end{array}$ & $\begin{array}{l}\text { Contextualization Principle } \\
\text { No. } \quad \% \text { of total }\end{array}$ & $\begin{array}{l}\text { Conceptualization Principle } \\
\text { No. } \quad \% \text { of total }\end{array}$ \\
\hline New Words & $\begin{array}{ll}0 & 0 \\
\end{array}$ & $\begin{array}{ll}4 & 100 \\
\end{array}$ & $4 \quad 100$ \\
\hline Reading & 100 & 100 & 50 \\
\hline Speak Out & 25 & 75 & 20 \\
\hline Write It Down & 0 & 25 & 25 \\
\hline Lan. Functions & 0 & 100 & 100 \\
\hline Pronunciation & 0 & +2 & 0 \\
\hline
\end{tabular}

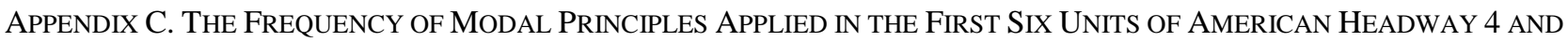
ITS TEACHER'S EDITION.

\begin{tabular}{|c|c|c|c|}
\hline Unit Sections & $\begin{array}{l}\text { Modal Flow Principle } \\
\text { No. } \quad \% \text { of total }\end{array}$ & $\begin{array}{l}\text { Contextualization Principle } \\
\text { No. } \quad \% \text { of total }\end{array}$ & $\begin{array}{l}\text { Conceptualization Principle } \\
\text { No. } \quad \% \text { of total }\end{array}$ \\
\hline Grammar & 16.6 & 100 & 50 \\
\hline $\begin{array}{ll}\text { Vocabulary } & \& \\
\text { Pronunciation } & \end{array}$ & 16.6 & 83.3 & 66.6 \\
\hline Reading \& Speaking & 100 & 100 & 83.3 \\
\hline Listening \& Speaking & 83.3 & 100 & 66.6 \\
\hline Every day English & 50 & 100 & 100 \\
\hline Writing & 33.3 & 100 & 100 \\
\hline
\end{tabular}

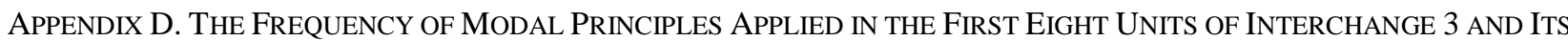
TEACHER'S EDITION.

\begin{tabular}{|c|c|c|c|c|c|c|}
\hline Unit Sections & $\begin{array}{l}\text { Moo } \\
\text { No. }\end{array}$ & $\begin{array}{l}\text { w Principle } \\
\% \text { of total }\end{array}$ & \multicolumn{2}{|c|}{$\begin{array}{l}\text { Contextualization Principle } \\
\text { No. } \% \text { of total }\end{array}$} & \multicolumn{2}{|c|}{$\begin{array}{l}\text { Conceptualization Principle } \\
\text { No. } \% \text { of total }\end{array}$} \\
\hline Snapshot & 8 & 100 & 8 & 100 & 8 & 100 \\
\hline Conversation & 8 & 100 & 8 & 100 & 8 & 100 \\
\hline Pronunciation & 3 & 37.5 & 2 & 25 & 0 & 0 \\
\hline Grammar $F$. & 15 & 93.7 & 16 & 100 & 7 & 43.7 \\
\hline Listening & 7 & 53.8 & 13 & 100 & 2 & 15.3 \\
\hline Speaking & 0 & 0 & 26 & 100 & 8 & 30.7 \\
\hline Writing & 0 & 0 & 6 & 75 & 8 & 100 \\
\hline Word Power & 2 & 25 & 4 & 50 & 6 & 75 \\
\hline Perspectives & 5 & 62.5 & 8 & 100 & 3 & 37.5 \\
\hline Interch. Activity & 0 & 0 & 8 & 100 & 4 & 50 \\
\hline Reading & 8 & 100 & 8 & 100 & 4 & 50 \\
\hline
\end{tabular}

Note: Grammar F. (Grammar Focus), Interch. Activity (Interchange Activity). 


\begin{tabular}{|c|c|c|c|c|c|c|}
\hline \multirow[t]{2}{*}{ Unit Sections } & \multirow{2}{*}{$\begin{array}{l}\text { Modal Flow } \\
\text { No. }\end{array}$} & \multirow{2}{*}{$\begin{array}{l}\text { Principle } \\
\% \text { of total }\end{array}$} & \multicolumn{2}{|c|}{ Contextualization Principle } & \multicolumn{2}{|c|}{ Conceptualization Principle } \\
\hline & & & No. & $\%$ of total & No. & $\%$ of total \\
\hline Preview \& Introduction & 5 & 100 & 5 & 100 & 5 & 100 \\
\hline Conversation Lesson & 5 & 100 & 5 & 100 & 5 & 100 \\
\hline Grammar Lesson & 5 & 100 & 5 & 100 & 3 & 60 \\
\hline Reading Lesson & 3 & 60 & 5 & 100 & 2 & 40 \\
\hline Listening Lesson & 5 & 100 & 5 & 100 & 4 & 80 \\
\hline Writing & 0 & 0 & 4 & 80 & 1 & 20 \\
\hline
\end{tabular}

APPENDIX F. THE IDENTIFIED OCCURRENCES OF MODAL FLOW PRINCIPLE IN ENGLISH BOOK 1

\begin{tabular}{|l|l|l|}
\hline Unit Sections & No. of Occurrence & Page No. \\
\hline New Words & 0 & \\
\hline Reading & 5 & $11,24,36,46,61$ \\
\hline Speak Out & 1 & 38 \\
\hline Write It Down & 0 & \\
\hline Lan. Functions & 0 & \\
\hline Pronunciation & 0 & \\
\hline
\end{tabular}

APPENDIX G. THE IDENTIFIED OCCURRENCES OF MODAL FLOW PRINCIPLE IN ENGLISH BOOK 2

\begin{tabular}{|l|l|l|}
\hline Unit Sections & No. of Occurrence & Page No. \\
\hline New Words & 0 & \\
\hline Reading & 4 & $4,16,32,45$ \\
\hline Speak Out & 1 & 18 \\
\hline Write It Down & 0 & \\
\hline Lan. Functions & 0 & \\
\hline Pronunciation & 0 & \\
\hline
\end{tabular}

APPENDIX H. THE IDENTIFIED OCCURRENCES OF MODAL FLOW PRINCIPLE IN AMERICAN HEADWAY 4

\begin{tabular}{|l|l|l|}
\hline Unit Sections & No. of Occurrence & Page No. \\
\hline Grammar & 1 & 22 \\
\hline Vocabulary \& Pronunciation & 1 & 25 \\
\hline Reading \& Speaking & 6 & $6,17,26,34,44,54$ \\
\hline Listening \& Speaking & 5 & $10,28,33,48,53$ \\
\hline Every day English & 3 & $29,39,49$ \\
\hline Writing & 4 & $112,115,117,118$ \\
\hline
\end{tabular}

APPENDIX I. THE IDENTIFIED OCCURRENCES OF MODAL FLOW PRINCIPLE IN INTERCHANGE 3

\begin{tabular}{|l|l|l|}
\hline Unit Sections & No. of Occurrence & Page No. \\
\hline Snapshot & 8 & $2,8,16,22,32,36,44,50$ \\
\hline Conversation & 8 & $2,11,16,25,33,38,47,52$ \\
\hline Pronunciation & 3 & $12,46,51$ \\
\hline Grammar $\boldsymbol{F}$. & 15 & $3,6,9,11,17,23,25,31,33,37,39,45,47,51,53$ \\
\hline Listening & 7 & $14,18,24,34,38,43,46$ \\
\hline Speaking & 0 & \\
\hline Writing & 0 & \\
\hline Word Power & 2 & 30,54 \\
\hline Perspectives & 5 & $5,8,22,30,44$ \\
\hline Interch. Activity & 0 & \\
\hline Reading & 8 & $7,13,21,27,35,41,49,55$ \\
\hline
\end{tabular}

APPENDIX J. THE IDENTIFIED OCCURRENCES OF MODAL FLOW PRINCIPLE IN SUMMIT 1

\begin{tabular}{|l|l|l|}
\hline Unit Sections & No. of Occurrence & Page No. \\
\hline Preview \& Introduction & 5 & $2,14,26,38,50$ \\
\hline Conversation Lesson & 5 & $6,16,30,42,52$ \\
\hline Grammar Lesson & 5 & $4,18,28,40,54$ \\
\hline Reading Lesson & 3 & $8,32,58$ \\
\hline Listening Lesson & 5 & $10,22,32,44,56$ \\
\hline Writing & 0 & \\
\hline
\end{tabular}




\section{REFERENCES}

[1] Antenos-Conforti, E. (2001). The teaching of Elementary Italian as a Second Language in Canadian Universities: Methodologies, Curricula and Future Considerations. Unpublished Doctorial Dissertation, University of Toronto, Canada.

[2] Birjandi, P. (1994). Teacher's Guide Book 1 and 2. Tehran: Iran Publications.

[3] Birjandi, P., Soheili, A., Noroozi, M., \& Mahmoodi, Gh. H. (2008). English Book 1. Tehran: Iran Publications.

[4] Birjandi, P., Noroozi, M., \& Mahmoodi, Gh.H. (2009). English Book 2. Tehran: Iran Publications.

[5] Cicogna, C. \& Nussel, F. (1993). Neuropedagogy and the Teaching of Italian. AATI Newsletter, 3-6.

[6] Colella, C. (1999). Renzo Titone's Holodynamic Mode1 for Language Behavior and Language Learning: Implications and Applications for the Second Language Teaching. Unpublished Doctoral Dissertation, University of Toronto, Canada.

[7] Danesi, M. (1986). Research on the Brain's Hemispheric Functions: Implications for Second Language Pedagogy. Lenguas Modernas, 13, 99-113.

[8] Danesi, M. (1987). Practical applications of current brain research to the teaching of Italian. Italica, 64(3), 377-392.

[9] Danesi, M. (1988). Studies in Heritage Language Learning and Teaching. Toronto: Centro Canadese Scuola e Cultura Italiana.

[10] Danesi, M. (1992). Metaphorical competence in the second language acquisition and second language teaching: The neglected dimension. In J. E. Alatis (Ed.), Language, Communication, and Social Meaning. Georgetown University Round Table on Languages and Linguistics. Washington, DC: Georgetown UP, 489-500.

[11] Danesi, M. (1993). Vico, Metaphor, and the Origin of Language. Bloomington: Indiana University Press.

[12] Danesi, M. (1998). II cervella in aula! Neurolinguistica e didattica delle lingue. Perugia: Edizioni Guerra.

[13] Danesi, M. (2003). Second Language Teaching: A View from the Right Side of the Brain. The Netherlands: Kluwer Academic Publishers.

[14] Danesi, M. and Mollica, A. (1988). From Right to Left: A "Bimodal" Perspective of Language Teaching. Canadian Modern Language Review, 45(1), 76-0.

[15] Ellis, R. (2003). Task-based Language Learning and Teaching. Oxford: Oxford University Press.

[16] Jeffries, S. (1985). English Grammar Terminology as an Obstacle to Second Language Learning. Modern Language Journal, $69,385,390$

[17] Kim-Rivera, E. G. (1998). Neurolinguistic Applications to SLA Classroom Instruction: A Review of the Issues with a Focus on Danesi's Bimodality. Texas Papers in Foreign Language Education, 3(2), 91-103.

[18] Kumaravadivelu, B. (1994). The post method condition: (e)merging strategies for second/foreign language teaching. TESOL Quarterly, 28(1) 27-48.

[19] Larsen-Freeman, D. (1999, October). On the appropriateness of language teaching methods in language and development. Paper presented at the Fourth International Conference on Language and Development, Hanoi. Retrieved October 3, 2010, from http://www.languages.ait.ac.th/hanoi_proceedings/larsen-freeman.htm.

[20] Mollica, A. \& Danesi, M. (1998). The Foray into the Neurosciences: Have We Learned Anything Useful?.In A. Mollica (Ed.), 201-215.

[21] Richards, J., Hull, J., Proctor, S. (2005a). Interchange 3( $\left.3^{\text {rd }}\right)$. Cambridge: Cambridge University Press.

[22] Richards, J., Hull, J., Proctor, S. (2005b). Interchange: teacher's edition 3( $\left.3^{\text {rd }}\right)$. Cambridge: Cambridge University Press.

[23] Saslow, J., Ascher, A. (2006). Summit: English for Today's World 1. Longman: Pearson Education.

[24] Saslow, J., Ascher, A., Tiberio, S.C. (2006). Summit 1: Teacher's Edition and Lesson Planner. Longman: Pearson Education.

[25] Sheldon, L. (1988). Evaluating ELT textbooks and materials. ELT Journal. 42(40), 237-246.

[26] Soars, L., Soars, J. (2005). American Headway 4. Oxford: Oxford University Press.

[27] Soars, L., Soars, J., \& Sayer, M. (2005). American Headway Teacher's Book 4. Oxford: Oxford University Press.

[28] Ur, P. (1996). A course in language teaching: Practice \& Theory. Cambridge: Cambridge University Press.

[29] Williams, D. (1983). Developing Criteria for textbook evaluation. ELT Journal. 37(3), 251-255.

[30] Young, B. A. \& Danesi, M. (2001). Studying How the Brain Learns: Are There Any seful Implications for Instruction? Retrieved July 4, 2010, from http://www.arrowsmithschool.org/howbrainlearns.htm.

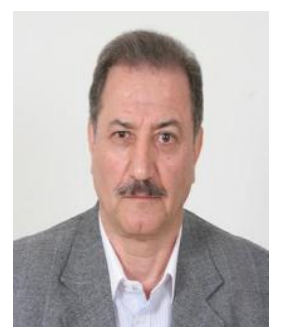

Mohammad Reza Talebinejad is an Associate Professor of Applied Linguistics at Islamic Azad University, Shahreza Branch. He is also an associate faculty member at Sheikhbahaee University, Iran.

Dr Talebinejad received his BA in English Language and Literature, University of Isfahan in 1975. He then got his MA in TEFL from the University of Texas at Austin, USA in 1977. For his doctoral degree, Dr Talebinejad was admitted to the University of Sheffield, UK, where he did his PhD in Applied Linguistics in 1994.

He has widely published in Iranian as well as International professional journals such as Metaphor and Symbol, English Teaching Forum, Language Testing, IJAl, Language and Translation, Journal of Social Sciences, The International Journal of Humanities, and other local and international journals. Dr Talebinejad has presented papers in International conferences such as AILA, 2000; Atiner, 2011; RAAM, 2002, 2001 in Paris and Tunis, EUROSLA, Switzerland, 2006; Multicultural Conference, 2007, China. In addition, Dr Talebinejad has authored/coauthored eight books in related fields and ESP. 
Masoud Mahmoodzadeh was born in Mashhad, Iran, in 1985. He received his B.A. in English Language Translation from Imam Reza University, Mashhad, in 2008. He furthered his university studies on English education for an M.A. degree in TEFL and earned his M.A. degree from Sheikhbahaee University, Isfahan, Iran, in 2011.

He is currently an EFL teacher working in the English language centers in Mashhad. He has been teaching English to Iranian EFL learners in several language institutes since 2004. Also, he has one year of experience in teaching General English courses at Sheikhbahaee University. His main areas of interests include second language acquisition and curriculum planning/evaluation. 